ISSN: $0120-8454 \quad \square \quad$ No. $76 \quad$ ㄱ pp. $23-46$

\title{
Dificultades teórico metodológicas de la propuesta intercultural de Raúl Fornet Betancourt ${ }^{1}$
}

\author{
Dr. Horacio Cerutti Guldberg² \\ Universidad Nacional Autónoma de México (UNAM)
}

Recibido: 8 de noviembre de 2009 - Aprobado: 3 de mayo de 2010

\section{esumen}

El siguiente estudio hace parte del análisis crítico que plantea el maestro Cerutti a la propuesta de la filosofía intercultural de Raúl Fornet-Betancourt. Mostrando las dificultades que se desprenden de las relaciones entre filosofía y cultura, el diálogo que propone Cerutti con Fornet-Betancourt confronta los presupuestos de una filosofía europea occidental, de cara a las manifestaciones plurales y diversas que caracterizan a la realidad latinoamericana, más allá de los lugares comunes, de los sesgos ideológicos, de las formas de recepcionar el pensamiento que viene de 'afuera', para así reconstruir una nueva manera de plantear y resolver los problemas metafísicos, antropológicos, epistemológicos, éticos y políticos que atañen a un estudio sistemático de la realidad que se vive en 'Nuestra América'.

Palabras clave: Interculturalidad, inculturación, identidad, persona, filosofía de la cultura.

1 Artículo de investigación, que se enmarca en la amplia serie de estudios que ha realizado el Dr. Horacio Cerutti sobre la realidad y la textualidad de 'Nuestra América'. El presente artículo fue publicado en Antonio Sidekum e Paulo Hahn (organizadores). Pontens interculturais. Sao Leopoldo, Nova Harmonia, 2007, pp. 9-23.

2 Horacio Cerutti es Licenciado y Profesor (Maestro) en Filosofía por la Facultad de Filosofía y Letras de la Universidad Nacional de Cuyo, Mendoza, Argentina (1973). Doctor en Filosofía por la Universidad de Cuenca, Azuay, Ecuador (1978). Becario de Posgrado en la Fundación Bariloche, Río Negro, Argentina (1976). Becario de Postdoctorado Fundación Alexander von Humboldt, Nürnberg, Alemania (1986). Ha sido Profesor en las Universidades de Salta, Argentina; de Cuenca, Ecuador y Pedagógica Nacional en México. Desde 1982 a la fecha, es catedrático de la Universidad Nacional Autónoma de México (UNAM). Entre sus obras cabe mencionar Filosofía de la liberación latinoamericaba. (2006 tercera edición), Configuraciones de un filosofar sureador(2005), Democracia e integración en Nuestra América (Ensayos) (2008). Correo electrónico cerutti@servidor.unam.mx: 


\section{Theoretical and methodological difficulties of intercultural proposal}

\section{A bstract:}

I can hardly do justice in these few lines to the already extensive work done in recent years by Raúl Fornet-Betancourt. It would be useless even trying to do it. Instead, I want to concentrate on some of his most significant contributions to highlight the most interesting things and express with rigorously and fraternally, perhaps some fruitful suggestions in view of future work. Everything as an enthusiast way to join the deserved tribute for his first sixty years of life was organized by other dear friends, including Sidekum Antonio, who has been kind for inviting me to participate. So I thought it is appropriate to break down the exhibition in three sections of unequal length: history, criticism and objections.

Keywords: Raúl Fornet-Betancourt, intercultural philosophy, ethics and politics intercultural, intercultural methodology. 


\section{Difficultés théorico-méthodologiques de la proposition interculturelle}

\section{Résumé}

Je pourrai difficilement rendre justice, dans ces brèves lignes, au travail déjà considérable, effectué ces dernières années par Raúl Fornet-Betancourt. II serait même inutile de prétendre le faire. Je préfère donc me concentrer sur quelques-uns de ses apports les plus significatifs pour en relever les aspects que je considère les plus intéressants et proposer, en toute rigueur et de manière fraternelle, quelques suggestions peut-être fécondes en vue de tâches futures. Tout cela vu comme une manière enthousiaste d'adhérer à I'hommage mérité organisé pour lui à l'occasion de ses soixante premières années de vie par d'autres chers amis, dont Antonio Sidekum, qui a eu la gentillesse, ce dont je le remercie beaucoup, de $m$ 'inviter à y participer. Pour atteindre mon objectif, j'ai cru convenable d'organiser mon exposé en trois parties de longueur inégale : trajectoire, autocritique et objections.

Mots-clé: Raúl Fornet-Betancourt, philosophie interculturelle, éthique et politique interculturelle, méthodologie de l'interculturalité. 
Debíamos desarrollar el pensamiento revolucionario sin olvidar que la actividad intelectual tiene sus reglas y sus problemas y acumulaciones propios, que no es una "forma"de un "contenido" que sería la "esencia" de lo social (...) Al mismo tiempo, afirmábamos que la tarea del intelectual no era repetir, escandalizar ni adornar, sino cumplir con los deberes específicos de la actividad intelectual, siempre atravesada por la política.

Fernando Martínez Heredia

Difícilmente podré hacer justicia en estas breves líneas a la ya amplia labor desplegada en estos años por Raúl. Inútil sería pretender siquiera intentarlo. Más bien, me quiero concentrar en algunos de sus aportes más significativos para relevar los aspectos que considero más interesantes y plantear, con todo rigor y fraternamente, en algunas sugerencias quizá fecundas en vistas de tareas futuras. Todo como un modo entusiasta de adherirme al merecido homenaje que por sus primeros sesenta años de vida se le organiza por parte de otros queridos amigos, entre ellos Antonio Sidekum, quien ha tenido la gentileza, que mucho agradezco, de invitarme a participar. Por ello, he creído conveniente organizar la exposición en tres apartados de desigual extensión: trayectoria, autocrítica y reparos.

\section{I}

\section{Itinerario por sendas ¿convergentes?}

En un sugestivo trabajo efectuado con gran afecto, Diana de Vallescar Palanca reconstruye la trayectoria de Raúl y sugiere una periodización en cuatro momento acotados cronológicamente de modo flexible, la cual surgiría de la propia autoimagen que reflejan sus textos.

1. Recepción de la filosofía europea (1978-1985), con dos momentos:

a. Recepción acrítica 
b. Inflexión (1984-1986)

2. Ruptura o tránsito hacia el modelo intercultural (1987-1994)

3. Un nuevo paradigma de la filosofía: la filosofía intercultural

Hacia una praxis ético-política de la interculturalidad (1995...). (Vallescar, 2001, pp. 81-90)

Me gustaría destacar algunos puntos del enfoque propuesto por Diana. Por ejemplo, el papel que Diana le atribuye a la Filosofía de la Liberación en el momento de inflexión de la primera etapa, particularmente por la manifiesta afinidad de Raúl con la versión inculturada de esas propuestas filosóficas americanas. La caída en cuenta posterior de Raúl acerca de la forma de sutil colonialismo (cursivas de la autora, seguramente para subrayar que son términos de Raúl) implicada en la propuesta de interculturación y la apreciable actitud consecuente de Raúl de avanzar más allá de ella. Con todo, creo que deben tomarse con ciertas preocupaciones afirmaciones como la siguiente: “... 'liberar' aquí implica no admitir ninguna forma de logos como referente absoluto para discernir lo filosófico"(Vallescar, 2001, p. 85) y, también, la asimilación de la palabra mito (Vallescar, 2001, p. 85). La primera afirmación, porque sería muy difícil y quizá imposible discernir sin logos y, aunque muy sutilmente, podría seguir operando cierto dogmatismo en la base de este discernimiento, como es constatable en más de un caso de presuntas novedades. La segunda, porque no se justifica asimilar sin más, la palabra logos (seguramente de pueblos originarios) al mito, cuando lo que (se) constata en las diversas formas de expresión humana es una compleja articulación de mythos y logos ${ }^{3}$. En cuanto a la tercera etapa, Diana no establece una delimitación temporal explícita, aunque parece considerarla como muy breve y concisa. En todo caso, según ella, en esta etapa Raúl se habría propuesto "aprender a pensar de nuevo" en el intento por cumplir con su aspiración a una"transformación intercultural de la filosofía". En la cuarta y, hasta ahora, última etapa de esta trayectoria, Raúl, según Diana, enfatizaría la "función" de la filosofía frente a la globalización,

3 He tratado de avanzar un poquito en esta compleja cuestión en un trabajo incluido en mi Configuraciones de un filosofar sureador. Orizaba, Veracruz, Ediciones del Ayutamiento de Orizaba, 1 reimpresión corregida, 2006 (la 1 ed. Es de 2005), pp.69 ss. 
evitando esencialismos y entendiendo - no por casualidad - la cultura como "visión del mundo que tiene algo que decir a todos", como "fomentadora de la "desobediencia cultural"'" y a "la propia cultura como una 'opción' dentro de la misma cultura" (Vallescar, 2001, pp. 87-88).

Armados con estas valiosas sugerencias, conviene que nos (re)internemos en algunos de los textos de Raúl, para examinar más cerca sus propuestas y procederes.

\section{II}

\section{Invitación a propiciar la crítica desde la autocrítica}

Es justamente Raúl el que enfatiza la necesidad de intensificar la crítica para avanzar en la construcción de alternativas viables que nos dignifiquen como humanos. Casi me permitiría añadir, que nos den oportunidad de seguir siendo humanos y de pugnar por desarrollar al máximo nuestras virtualidades creativas, dado que la añorada crítica constituye una especie de estribo para crecer y advertir facetas no suficientemente explicitadas de nuestros propios aportes. Raúl ejercita la crítica y autocrítica en sus trabajos, al menos de dos modos. Recordando a otros importantes autores que así lo han demandado, por una parte. Por la otra, predicándolo y practicándolo como si asumiera, por momentos, una postura de flamígero juez encargado de colocar las cosas en su lugar o de sacarlas de su presunto lugar para reubicarlas en el que, según él, les corresponde. Por supuesto, ambas modalidades son aportativas, tienen sus ventajas y sus evidentes limitaciones. Sobre todo, esta última, aparece como un mecanismo provocativo, el cual, al tiempo que procura eludir el argumento ad hominem, bordea peligrosamente la descalificación ideológica y hasta la desvalorización ética.

Convencido como estoy de que sin ejercicio obstinado de la crítica y la autocrítica difícilmente produciremos los aportes indispensables prácticoteóricos (tanto se han escindido'analíticamente' estas dos dimensiones, que no me canso de insistir en su indisoluble unidad fenoménico procesual en su ejercicio efectivo - ¡hasta me molesta tener que subrayarlo, pero resulta 
indispensable hacerlo uno y otra vez, además de mostrarlo manifiestamente en lo andado...!-, que la conflictiva social reclama para su transformación estructural -a estas alturas de la historia inescapable-, quiero insistir en examinar algunas aristas de estas modalidades puestas en obra por Raúl. Para evitar, de momento, presuntas objeciones que nos desviarían del itinerario buscado, conviene atender a que con lo afirmado sobre la inexplicable transformación estructural, no presupongo -jhuelga decirlo?- la existencia de ningún boceto perfecto - ni siquiera 'borroneado'- de cómo sería una presunta nueva sociedad. Dejo eso para divertimentos de cultivadores del género utópico, por lo demás siempre sugerentes.

Atendamos a la primera modalidad. En su estudio sobre el marxismo en nuestra América, pletórico de sugerencias, informaciones eruditas y que, aunque multicitado, espera todavía, hasta donde llega mi información de una merecida evaluación de su línea interpretativa ( $y$, consecuentemente, de los ejercicios de crítica que pone en obra), Raúl insiste en recordarnos la exigencia de crítica por parte de autores relevantes como tomar dos de sus ejemplos, el Che y Garcia Bacca. Señala a propósito de estos:

[...] o primeiro traco fundamental que, na mina opiniao, é realmente esencial para o marxismo de Guevara: o antidogmatismo [...] na concepcao de Guevara, a crítica e a autocrítica eran componenetes essenciais do proceso social da construcao do socialismo. (Löwy Michael, 1995, pp. 270-271)

Garcia Bacca trona o momento da crítica o fío conductor metodológico de su interpretacao de Marx [...] Para prevenir um eventual mal-entendido, debe-se, aliás, notar qui, que "transubstanciacao" e crítica significam para Garcia Bacca, no fundo, a mesma coisa: o método dialético (que permanece crítico) apara a discussao com a realidades [...] gostaria, no final, de resaltar precisamente esta preocupacao, porque pos er um notável contrapeso, respectivamente sinal de alerta contra a tendencia da re-utopizacao do socialismo[...] ( Löwy Michael, 1995, pp. 282-290).

La autocrítica, por su parte, la ejerce en relación con su adhesión a la perspectiva inculturada. En un trabajo de 1995 lo planteaba con toda claridad y conviene citarlo in extenso, porque aclara incluso algunas de las referencias y observaciones que recogimos más arriba de Diana de Vallescar. 
No puede pasarse por alto, en efecto, que la perspectiva de la inculturación de la filosofía implica una cierta trampa por cuanto que en ella se supone la "evidencia" de la existencia de un núcleo duro -fraguado precisamente en el curso del desarrollo histórico de la filosofía en Occidente- que habría que inculturar en las otras culturas.

Para concretizar esta observación crítica, cuya verdadera intención es la de Ilamar la atención sobre el sutil colonialismo que implica la idea de la inculturación, se puede pensar en las consecuencias a que conduce, por ejemplo, la idea de inculturar el logos griego- occidental con sus categorías racionalistas en las tradiciones de pensamiento indígena (Fornet-Betancourt, 2000, p. 55).

Aquí incluirá tres niveles: memoria simbólica, que quedaría "desestructurada"; el de la "palabra ("mito"), dado que las "palabras fundantes" quedarían "descolocadas", y el de la "tradición como formación viva de palabras fundantes" por su "dislocación".

Posteriormente, en 2001 insistiría, llamando la atención en nota, sobre su propia terminología:

Ponemos "proceso de inculturación" o "inculturación" entre comillas porque operamos aquí no con el concepto usual de este término, sino con la significación nueva del proceso intra-cultural que pone en marcha cualquier reflexión filosófica en la búsqueda de su autenticidad (Fornet-Betancourt, 2001, p. 36).

Para afirmar más adelante y con todo el énfasis necesario (remitiendo a un trabajo suyo de 1989 que no he podido consultar: "[...] ha llegado la hora de renunciar por completo al "concepto de inculturación" [...] más adecuado [... ] sería a lo mejor el concepto alternativo de inter-transculturación" ${ }^{5}$. (Fornet-Betancourt, 2001, p. 39)

En el mismo volumen incluye luego un artículo con un pequeño apartado, del cual difícilmente se podría descartar todo su valor, titulado"un momento

4 Cabe consignar que la segunda parte de este volumen reproduce los textos incluidos en: Interculturalidad y globalización...

5 Transformación intercultural..., p. 39 (cursivas mías).- 
de autocrítica". Allí deja Raúl bien clara su "corrección o rectificación", cuando señala: "retiro un punto de partida para proponer otro" (Fornet-Betancourt, 2001, p. 61). Y retoma la metáfora de José Martí en Nuestra América:"Injértese en nuestras repúblicas el mundo; pero el tronco ha de ser el de nuestras repúblicas."

Para añadir inmediatamente su propia interpretación:

Injertar el mundo en el tronco propio significa, a nuestro modo de ver-y por eso recurrimos a este texto martiano- darle la vuelta al problema [ o propuesta de nuevo punto de partida [...]. La cuestión no es ahora cómo integrar lo propio en el movimiento de lo" universal", sino cómo injertar la diversidad del mundo en lo propio.

Para dejar abierto, así el [...] "litigio de las filosofías" entre si, en el sentido fuerte de "pleito" entre diversos "logos filosóficos" (Fornet-Betancourt, 2001, pp. 65-67).

Quizá una de las más sutiles y sugestivas afirmaciones de Raúl al respecto, sea aquella en que considera al concepto de inculturación “[...] como un relicto del pasado hegemonial vinculado con la canonización de buena parte de la tradición filosófica de Occidente" (Fornet-Betancourt, 2001, p. 38). Relicto que yo dudaría en ubicar como de raíz francamente teológica. Más adelante me referiré al interesante paralelo con diversas modalidades de la teología, que Raúl examina cuidadosamente.

La crítica aparece, entonces, enunciada y hasta reclamada, por ejemplo, en los siguientes términos:

[...] consideramos que la articulación y la trasmisión de las ideas propias en forma de hipótesis a discutir, que quedan expuestas sin reserva alguna a la verificación o falsificación por los otros miembros de la "comunidad científica", son componente esencial de un estilo de pensar que favorece la cultura del

6 Quizá no esté demás consignar, aunque sea en nota al pie, que la seductora metáfora del tronco la propone y organiza Martí desde una visión filosófica de la historia que no es la propuesta por Raúl. De la inabarcable bibliografía sobre el Apóstol, quiero descartar la lectura muy recomendable de un libro reciente acerca de sus ideas filosóficas: Liliana Giorgis, José Martí. El humanismo como filosofía como filosofía de la dignidad. Mendoza, Ediciones del ICALA, 2006, 330 págs. 
diálogo y del intercambio de que tan necesitada está la filosofía en nuestro continente, y también en otras regiones del mundo (Fornet-Betancourt, 2001, p. 24).

Afirmación que no deja de ser sintomática. Porque o bien constituye un mero recurso de elegancia retórica, dado que aun cuando no se invitara a ello, resulta obvio que una propuesta cualesquiera fueran sus características queda sometida a la evaluación -que podrá efectuarse o no, en razón de la repercusión, me atrevo a decir, 'mercadológica' de la obra en cuestión- por parte de otros científicos o'cientistas' (¿en expresión limitativa muy usual...?) o bien resulta una 'confesión de parte', en el sentido de insistir en generalizar una posición monocultural (etnocentrista, eurocentrista, occidentalocentrista) muy característica del neopositivismo lógico y con una cierta concepción de ciencia supuesta7 . Pero, además, y quizá más grave todavía, dejando de lado a quienes no están- por descalificación o invisibilización previa cuasi ‘natural'- incluidos en la presuntuosa "comunidad científica". Quizá las comillas que utiliza en este caso Raúl sean un indicio de su uso acotado y yo concedería que hasta irónico, pero de todos modos aparece como francamente insuficiente la hora de ratificar esa posición: ¿Cómo sería el ejercicio del diálogo crítico si no fuera en términos de verificación o falsificación y por parte de 'expertos' o 'especialistas'? Es justamente lo que está por verse. Y para ello debe primar la apertura a otros códigos y a otros valores, incluso a otra concepción del saber y de la ciencia. Sin que esto implique presunciones acerca de su validez $y$, menos, acerca de los criterios que permitirían establecer esta validez... Significaría como bien dice Raúl, aceptar como interlocutores a otros "aún cuando a nuestros ojos no sean "filósofos"'" o - lo que es muchísimo peor- no lo sean a 'ojos' de la mentada 'comunidad [supuestamente] científica'" (Fornet-Betancourt, 2001, p. 89).

Por eso resaltan todavía más, si cabe, las valiosas palabras que incluye un poco más adelante:

7 Casi diría que es el mismo Raúl quien insinúa esta terminología ¿economicista?, cuando apela a una ¿metáfora? Que resulta quizá hasta incómoda cuando afirma que la postura intercultural supongo que inspirado por la crítica al "aldeanismo" de Martí-: "No es comarca sino comercio; no es retiro sino trato y contrato" (Fornet-Betancourt, 2001, p. 70). 
Quiera entonces el lector interesado leer las reflexiones que siguen como reflexiones que, lejos de hacer superflua su palabra y sus consideraciones, necesitan de éstas como de un elemento correctivo necesario en la búsqueda común de un filosofar más auténtico y, por ende, también más comprometido, más provechoso para América Latina (Fornet-Betancourt, 2001, p. 25).

Nada más que aquí también me permitiría sugerir limitar la cuestión a "provechoso", porque "más auténtico" y "más comprometido" constituyen descalificaciones implícitas de lo hecho, no siempre justificables y probablemente, descontextualizadas en su generalización.

Todo esto formaría parte, según Raúl de un escenario "estilo" "propositivo" (Fornet-Betancourt, 2001, p. 54). La novedad de esta propuesta estribaría en explicitar el riesgo ("arriesgar" dirá Raúl) que conlleva siempre una toma de posición teórico práctica (o sencillamente práxica, término en el que lo teórico quedaría ya implicado como consecutivo ineludible). Por lo cual, difícilmente podría aceptarse como una verdadera novedad, dado que siempre hay riesgo y siempre se pro-pone a la consideración. De los/as demás, aunque se presuma de hablar ex cátedra y hasta dogmáticamente ${ }^{8}$. Y es que una cosa es lo que se enuncia y otra cómo se lo recepta y no necesito recordar aquí los desarrollos sugerentes de la estética de la recepción, aunque no estaría demás tomarlos en consideración. Por otro lado, no dudo en afirmar que el estilo es el contenido sin más, aunque no sea éste el lugar para desarrollar acabadamente tan interesante cuestión, tratada con gran perspicacia por muchos/as otros/as autores/as.

8 En relación con esta dimensión no deja de ser sintomático que Raúl juegue peligrosamente, por así decirlo, con la noción de dogma para identificarla ni más ni menos que con la de idea reguladora, a partir de las consideraciones de Mariátegui, a quien cita a este respecto: "El dogma (esto es, la "idea reguladora", R.F.-B.) tiene la utilidad de un derrotero, de una carta geográfica[...] el dogma no es un itinerario sino una 'brújula en el viaje"', y añade un poco más abajo: "Creemos que la metáfora de la "brújula" es una feliz expresión[...]" (Cf. "Marxismo y filosofía" en: Ricardo Salas Astrain (coordinador académico), Pensamiento Crítico Latinoamericano. Conceptos Fundamentales. Santiago de Chile, Ediciones Universidad Católica Silva Henríquez, 2005, p. 635). 


\section{III}

\section{Reparos a algunas propuestas y a ciertos procedimientos}

Sin proponer aquí un orden de prioridades, me voy a detener en ciertos reparos que me surgen de los sugerentes esfuerzos intelectuales, ideológicos y políticos de Raúl.

\section{a. Cultura, inculturación, interculturalidad, identidad y persona:}

Aunque la interculturalidad de la filosofía aparezca permanentemente sugerida como propuesta hipotética, sus modos de proceder metodológicos, sus modalidades procedimentales, su misma argumentación requieren revisión detallada y adelantan ya, cualquiera fueran sus manifestaciones plenas y no meramente programáticas, ciertas dificultades. Reducir las críticas y los reparos a una interculturalidad lastrada por la inculturación, sería sólo una salida fácil e insuficiente ${ }^{9}$. Y esto, porque quizá lo más delicado sea la subjetivación de la cultura, con evidentes riesgos organicistas y con el agravante de eludir el meollo del conflicto económico social, sin que con ello me proponga reivindicar ninguna metáfora base/superestructura. En estas consideraciones asumo el desafío epistemológico de pensar las ciencias sociales, propuesto en su oportunidad por Immanuel Wallerstein.

Por momentos, la noción de cultura parece volverse trivial y hasta innecesaria o superflua.

O sea que no hay cultura sin materialidad interpretada u organizada por fines y valores representativos y específicos de una sociedad o etnia humana. En concreto: hay cultura allí donde las metas y valores por los que se define una comunidad humana, tienen incidencia efectiva en la organización social del universo contextual- material que afirman como propio porque están en él (Fornet-Betancourt, 2000, p. 19).

9 A propósito, parecieran ser los años 1989-1990 los que Raúl da como fechas de inicio de la propuesta intercultural (Fornet-Betancourt, 2001, p. 27). Para un panorama inicial de la propuesta de inculturación, consultar el sugerente estudio crítico de Olga Galindo López, "La filosofía inculturada ¿una alternativa social para América Latina? En: Islas. La Habana. Universidad Central de las Villas, Santa Clara, Cuba, n' 99, mayo 1991, pp.5-14. 
Y cómo podrían no estar o no afirmarlo, me pregunto: ¿Es que acaso hay alguna nuestra en la historia y en el globo en donde no se haya efectuado lo que aquí se postula? Y, en ese caso, qué se gana con postularlo o prestarle atención como algo decisivo, si es ingrediente propio del vivir humano como tal, dondequiera y cuandoquiera que se manifieste. $Y$ no deja de ser así, aunque se esgrima la autoridad de Herbert Marcuse al respecto. Tampoco se resuelve el problema calificando de "estabilizadas" ciertas tradiciones culturales, aún cuando sea seductora la consigna de "desobediencia cultural" (Fornet-Betancourt, 2000, p. 16). Y es que siempre una cultura está parcialmente estabilizada y también desestabilizada; abierta o sometida a la desestabilización. Tampoco pareciera ganarse demasiado...Y no obstante lo valiosa que resulta esta "desobediencia" como "instrumento para evitar la sacralización de las culturas [supuestamente estabilizadas]", resulta que todo argumento da una vuelta más tuerca para culminar sacralizando lo que denominaría un 'gran' sujeto: la cultura... o, mejor, las culturas que luchan entre sí, se defienden, son agredidas, etc. ${ }^{10}$ (Fornet-Betancourt, 2000, p. 19). Por cierto que asumo que estamos aquí ante trabajos elaborados en diferentes etapas de la producción de Raúl. Pero, recojo estas dificultades porque creo que, a pesar de su valiosísima autocrítica, permanecen insistentemente en su lenguaje y significan soportes y hasta fundamentos de su argumentación.

Quizá para evitar esa trivialización de la definición de cultural, incluso, hacerla innecesaria, habría valido más la pena prolongar el uso controlado de la denigrada noción de weltanschauung, tal como fue anticipada por Diana de Vallescar, retomando oportunamente la terminología utilizada por el

10 Sería muy largo reproducir aquí todos los lugares en que la cultura aparece como el sujeto. Y no se trata sólo de un modo de hablar... La Filosofía de la cultura ronda por aquí, aunque sea repudiada. Incluso en otros autores en quienes repercute la preocupación, se advierte este énfasis. Como muestra se puede retomar la siguiente definición de interculturalidad: "[...] forma práctica de establecer una forma de reconocimiento teórico y práctico: contextual, histórico social y cotidiano, de la diversidad de culturas y de las culturas con respecto a si mismas" (Octavio Obando Morán), "Mundialización, interculturalidad y desenvolvimiento de algunos problemas filosóficos en la tradición socialista del Perú: 1970-2000" en: Reflexión y crítica. Revista de filosofía. Lima, UNMSM, año 9, n' 5, septiembre 200, p.50). Y también la siguiente demanda: "Se requiere, pues, de un acto dinamizador de la revitalización de las culturas marginadas, que sobreviven como un acto heroico de la fuerza que le da su perspectiva y la voluntad de continuidad de su existencia" (Dora Vidal Alva,"la filosofía intercultural y la filosofía latinoamericana" en: Reflexión y crítica. Revista de Filosofía. Lima, UNMSM, año 7, n' 3, marzo 2003, p.64). 
mismo Raúl ${ }^{11}$. Probablemente habría que atreverse a ello, a pesar de que la noción fue descalificada por la conocida como"normalización"filosófica.

Aquí no estaría demás recordar algunos anticipos de estas cuestiones en los ¿lejanos? años setenta del siglo pasado. Osvaldo Ardiles, seguramente el más creativo e innovador de los filósofos populistas de la liberación -lo cual constituye una constatación fáctica y no una imputación o descalificación ideológica, dado que ellos mismo se reconocieron así y muchos no dudaron en asumirla como posición político ideológica que exhibían y reivindicaban, incluso muchos años después, como la propia y más valiosa- dedicó interesantes reflexiones a la cuestión de la cultura ${ }^{12}$. Sobre todo en unos trabajos prácticamente desconocidos editados en México. Quisiera recordar algunas de sus finas observaciones a continuación, las cuales permiten retomar cuestiones tales como: la dimensión antropológica de la cultura, su exterioridad constitutiva, su cercanía con la cosmovisión o visón del mundo, sus relaciones con la noción de filosofía, la noción de pueblo críticamente situada en el seno del conflicto social, la manipulación cultural en situaciones de dependencia, etc.

Esta transformación, por lo cual el hombre confiere a la naturaleza atributos antropológicos, se llama 'cultura'13.

Siempre hubo un universo exterior a la cultura, que comprendía al Enemigo, el otro, al Extranjero, al Paria, etc. (Ardiles, 1980. p. 165).

11 "La cultura es pues "una visión del mundo que tiene algo que decir que todos"..."en: Semillas..., p. 87. Y Raúl: “... en el reconocimiento real de cada cultura como visión del mundo que tiene algo que decir a todos...", "Por la reflexión el ser humano puede ver la cultura que lo hace, puede ver la visión del mundo con la que ve y se ve" (Interculturalidad y globalización..., pp.24 y 36, cursivas en el original).

12 Para esta y otras consideraciones acerca de los orígenes de la filosofía de la liberación me permito remitir a mi Filosofía de la Liberación latinoamericana. México, FCE, 3 ed, corregida y ampliada [la 1 es de 1983],2006, 527 págs.-

13 Osvaldo Ardiles, Vigilia y utopía. Problemas de la filosofía contemporánea. Guadalajara, Universidad de Guadalajara, 1980, p.163, negritas en el original. Sobre estos autores hay algunas referencias en trabajos de Raúl como "La filosofía de la liberación en América Latina" en: Eudaldo Forment (coordinador del curso y de la edición), Filosofía de Hispanoamérica. Aproximaciones al panorama actual. Barcelona, Universitat de Barcelona, 1987, pp 123-150 y "Tesis para la comprensión y práctica de la interculturalidad como alternativa a la globalización” en: Antonio Jiménez García (editor), Estudios sobre Historia del Pensamiento Español. Santander, Asociación de Hispanismo Filosófico/ Fundación Histórica Tavera/ Sociedad Menéndez Pelayo, 1998, pp. 387-394. 
La articulación de los principios más generales de la praxis así entendida, de las determinaciones presentes en sus más diversos momentos estructurales y de las categorías del quehacer ideológico-cultural, configuran una visión crítica del "mundo", la cual, entendida, de las determinaciones presentes en sus más diversos momentos estructurales y de las categorías del que hacer ideológico-cultural, configuran una visión crítica del "mundo", la cual, entendida como'pensamiento estratégico del pueblo', puede con toda propiedad ser llamada'filosofía' (Ardiles, 1980. p. 244. Negrita en el original).

\section{Entendemos por pueblo al conjunto de sectores sociales explotados} (condición objetiva) y en lucha contra el imperialismo y la dependencia interna y externa (condición subjetiva) (Ardiles, 1980. p. 245. Negritas en el original).

Visualizando la dependencia estructural como factor permanente en nuestra historia, se comprenden las múltiples mediaciones a través de las cuales se impuso la dominación. Su resultado fue la consolidación de una sociedad escindida, marginal a la historia, deformada por pautas inauténticas, por impropias, de conducta, y una cultura oficial domesticadora extraña al destino de los hombres que lo sustentan. Esta obra "cultural" tuvo como objetivo introyectar sentimientos de inferioridad, aniquilar la especificidad histórica de nuestra nacionalidad y anestesiar la consciencia de nuestro pueblo para hacerlo ejecutar en forma sumisa y resignada los proyectos de la dominación (Ardiles, 1980. p. 246).

En un artículo reciente, otro de los fundadores de la filosofía de la liberación, Aníbal Fornari, nos sugiere algunas pistas valiosas para futuras reflexiones acerca del modo cómo se conceptúa la comunidad y los sujetos. La comunidad sería un acontecimiento revolucionario, radicalmente alterativo en su sustentación y personal en su adhesión y verificación, en el que imprevistamente se encuentran lo que ante todo son extraños entre sí ${ }^{14}$.

14 Aníbal Fornari, "La pregunta por el sujeto histórico. Consideraciones preliminares sobre su exigencia socio-política y su problemática historicidad" en: Utopía y praxislatinoamericana. Maracaibo, Universidad del Zulia, año 11, n'35, octubre-diciembre 2006, p.36, cursivas en el original. Fornari se extiende luego en los riesgos de lo que entiende como características del fenómeno "gnóstico" aplicadas a la visión de la historia (cf. p. 43 hasta el final), cuestión en la que no vamos a entrar aquí, no por desestimarla, sino porque nos desviaría de los objetivos inicialmente propuestos para el presente trabajo.- 
Estas consideraciones de Fornari vienen muy a cuento de una cuestión que Raúl deja abierta en una importante referencia en nota a uno de sus artículos, cuando señala que:

Dejo anotado que éste sería el lugar [¿el del "litigio" intracultural?] para analizar la diferencia entre "cultura" $y$ "sociedad", ver las formas de interacción entre ambos niveles y plantear la cuestión de si las culturas, por la tendencia integrativa que les es constitutiva, no son el foco que mantiene viva la posibilidad de la "relación comunitaria", de la comunidad, en las sociedades complejas de hoy ${ }^{15}$.

En un texto reciente a propósito de la situación educativa española, dos autoras proporcionan aportes significativos para prolongar estas reflexiones. Se ha elegido el término Educación Intercultural, por entender que en la coyuntura multicultural actual es preciso ir más allá de la mera coexistencia de culturas, para pasar a una convivencia real que implique reconociendo, valorización, diálogo y participación. Tal como lo recoge el proyecto 7 del CDCC Del Parlamento Europeo (1986), es necesario realizar la transición de la multiculturalidad a la interculturalidad, lo que supone fomentar un dinamismo de comunicación e interacción ${ }^{16}$.

Pero, a pesar de todos los esfuerzos institucionales e individuales, las autoras constatan que sigue predominando un énfasis en una cierta 'racionalidad 'presuntuosamente colocada por encima de las funciones actitudinales humanas. A la postre, sigue imperando un enfoque logo céntrico en el que las actitudes son asunto de segundo orden (Iriarte y Naval, 2006. p. 239). Constatación que lleva a las autoras a propiciar cambios estructurales más de fondo, como único modo de avanzar en estos objetivos tan loables y poder superar así los supuestos buenos deseos ${ }^{17}$ :

15 "Filosofía intercultural" en: Ricardo Salas Astrain (coordinador académico), Pensamiento Crítico Latinoamericano. Conceptos Fundamentales. Santiago de Chile, Ediciones Universidad Católica Silva Henríquez, 2005, p.410, nota 14.-

16 Concha Iriarte y Concepción Naval, "En torno a la educación intercultural en el ámbito escolar en España" en: Graciela A. Mota (coordinación y edición), Educación cívica y ciudadana: una visión global. Dignidad, identidad y participación en la construcción de sociedades democráticas. México, Aula XXI/Santillana/ México, 2006, p.233, nota 2.

17 "Todos somos distintos, pero todos somos iguales [...]" Ésta es quizá una de las trampas más llamativas en las que se ha caído en la construcción de los discursos interculturales. Esta frase con alto impacto y alto contenido metafórico se ha convertido en bandera de tolerancia y de no discriminación. Pero debemos reflexionar sobre el absurdo de la misma: ¿cómo se puede ser igual a algo y a la vez diferente de ese algo? 
[...] en las propuestas educativas no se plantea que el cambio de creencias pueda generar por sí sólo transformaciones reales en la sociedad; todo lo contrario, hay que comprometerse para socavar las estructuras sociales que se consideran opresoras, así como los soportes ideológicos en los que se apoyan. La educación en este enfoque estará muy ligada a la acción política (Iriarte y Naval, 2006. p. 246).

Para terminar afirmando que, en verdad se trata de "[...] potenciar lo más radicalmente educativo: las personas"18 (Iriarte y Naval, 2006. p. 256). Lo cual nos recuerda, desde la perspectiva pedagógica y, más en general, educativa que en el enfrentamiento y el conflicto se da siempre entre personas con códigos, valores y pautas o hábitos culturales diversos. Son las personas lo relevante y no las culturas que a nadie interesa guardar en formol o a en acumulaciones museales y esto sin desvalorizar el acopio de los museos y la experiencia de visitarlos, que puede ser muy productiva, depende cómo se la viva ${ }^{19}$.

\section{b. Nombres "mayores" y"menores"}

Se mezclan planos de rango distinto: el derecho a ser tratado con igualdad con el deseo identitario de definirse diferente de otro : "[...] ¿No será ésta una "nueva" manera de construir con dulzura la diferencia desigual invocando ahora los acordes del reconocimiento de la diversidad?" (p.247, nota 10).

18 Esto sin dejar de consignar el soporte 'empírico' de un estudio estadístico, según el cual un "[...] 83\% de los encuestados admitió como válido el concepto de raza [...]” (p.253). No puedo menos que recordar aquí, también, la atinada crítica al culturalismo de Carlos Molina Jiménez cuando señalaba: "[...] basta un examen atento para darse cuenta de que en el discurso identitario de nuestros filósofos, en su conformación básica, suelen estar presentes elementos como el resentimiento histórico; el pensamiento desiderativo y consolador, que sustenta una falsa autoestima; la autocompasión más o menos plañidera; la estratagema de las uvas verdes como recurso de autoengaño; la atribución de la máxima responsabilidad por nuestros males al otro; la actitud acrítica y apologética respecto de nuestras propias pautas culturales; la convicción de que si nos dejaran ser, seríamos una maravilla [...]" ("La cuestión de la identidad cultural latinoamericana" anexo a: Realización y crisis de la democracia representativa: dos ensayos sobre los avatares de una idea en la historia. Heredía, Costa Rica, Universidad Nacional, 2003, p.186). O, en otro contexto, aquella de Jorge J.E. Gracia cuando criticaba a los culturalistas "[...] porque se aprovechaban de la ambigüedad del lenguaje oscuro que usan para expresarse" (Filosofía hispánica. Concepto, origen y foco historiográfico. Navarra, Universidad de Navarra, 1998, p.92).

19 Así creemos que lo planteaban con todo rigor Pablo Guadarrama González y Nokolai Pereliguin, lo universal y lo específico en la cultura. Bogotá, Universidad Central de las Villas, Santa Clara, Cuba/ Universidad INCCA de Colombia, 1998, especialmente en pp.19,24,29,30 y 46.-

20 Uno de los más importantes para Raúl es Jean Paul Sartre, a quién no dudaron en (des) calificar como "intruso" en el marxismo. Tal es el caso de Erich Fromm. Para calibrar adecuadamente este antecedente habría que revisar con mucho cuidado el reciente estudio de Alfredo Gómez Müller, Sartre de la nausée á l' engagement. París, Editions du Félin, 2005, 233 págs. 
él. Es como si los destacara por sus carencias. Lo cual, en principio, no está mal, siempre y cuando apreciara sus aportes. Esto conlleva también una continua no referencia a la tradición filosófica latinoamericana o a referencias muy poco contextualizadas. Quizá por la atención muy desigual que Raúl le presta a los aportes de nuestra tradición en Historia de las Ideas. Siempre mencionada, pero poco aprovechaba. Lo que suele reiterar es una descalificación por mono-cultural, aplicable en no pocos casos, pero inconsistente en su generalización. Por ello, quizá, no se vislumbran en sus enfoques "nuevos accesos" efectivos a la Historia de las Ideas, a la cual no se puede, por lo demás, hacer referencia en bloque, dadas las múltiples y hasta sutiles variantes desarrolladas a su interior y que merecen ser conocidas y evaluadas con precisión (Fornet-Betancourt, 2001, p. 77 y ss.). Me da la sensación de que la propuesta intercultural de Raúl no termina de lograr el des [a]marre" de la tradición occidentalocéntrica (Fornet-Betancourt. 2001. p. 84). Por ello, deberíamos cuidarnos de que la postulada "revisión de nuestros hábitos de pensar" o la radicalización de la "Revolución der Denkart" kantiana cayera en un nuevo gattopardismo (Fornet-Betancourt. 2001. p. 92). Un aporte muy significativo de Raúl, que desarrollado permitiría eludir estos riesgos, lo constituye la comparación que efectúa con diferentes manifestaciones teológicas en un esfuerzo por lograr la fecundación interdisciplinar ${ }^{21}$ (FornetBetancourt, 2001, pp. 125-167). Lo más destacable consiste, a mi juicio, en el esfuerzo por deslindarse de la "actitud "misionera" "agresiva", infelizmente no depuesta definitivamente, y por avanzar en el difícil distanciamiento del supuesto paradigma cristiano (hasta hace unos años predominantemente católico) de la'auténtica' teología. Sin hablar de la imposición a sangre y fuego, simbolizada en la que Antonio Cornejo Polar calificara sugerentemente de "escena originaria" (como el "diálogo" en el área andina entre Atahualpa y el padre Valverde y que me permitió extender al sostenido entre los primeros franciscanos en arribar a la Nueva España (sic) y los tlamatinime..., tal como fuera puesto generosamente a disposición por Miguel León Portilla).

Con todo, podría señalar que las otras voces, las de los pueblos originarios, no son muy tomadas en cuenta, salvo por traducciones (¿tradittoras?) muy

21 CF. El apartado "3. La teología latinoamericana..." en: Transformación intercultural. 
discutibles. Aquí es donde convendría llamar la atención sobre las críticas del filósofo peruano Mario Mejía Huamán, cuya lengua materna es el quechua. Mario insiste en varios puntos que, por su sólida formación en lógica, le aparecen como poco pertinentes y hasta inválidos.

Apunta, entre otras, los siguientes, cuya pertinencia no me puedo detener a establecer aquí: ineficacia del contraste de voces, las ideas no son asimilables sin más mercancías, falta de precisión en la determinación de los centros del eurocentrismo, advertencia de escasa voluntad de cambio estructural por parte de opresores o beneficiarios ricos del sistema imperante, insuficiencia de la solidaridad, falta de originalidad y/o novedad ${ }^{22}$.

Por otra parte, no puedo menos que rechazar de plano la desafortunada denominación que hace Raúl de autores "menores"..., la cual no se hasta qué punto constituyó una gaffe (¡premeditada?), pero en todo caso inapropiada en tanto constituye una implícita descalificación:

Es verdad que me refiero a filósofos mucho menos conocidos cuyas obras, además, no son reconocidas ('¿todavía?) como obras de obligada consulta para estar al tanto de las "consignas" vigentes en el quehacer filosófico actual en nuestras latitudes [...] que acaso podrían ser catalogados como"nombres menores" [...] autores y autoras cuya obra no es reconocida todavía como

22 Mario Mejía Huamán, "Transformación intercultural de la filosofía. Comentario desde la óptica de la filosofía. Comentario desde la óptica andina" en: Hacia una filosofía andina. Doce ensayos sobre el componente andino de nuestro pensamiento. Lima, [edicción del autor], 2005, p.207, cursivas en el original. En todas las citas que hago de este texto respeto la puntuación original y sólo me permito corregir las que son evidentes erratas' de dedo' u ortográficas."... su propuesta está fuera de onda [...] la armonía no surge del simple contraste entre las voces, como parece entender el autor [...] La bulla de los mercados "informarles" limeños por ejemplo, no es armónica, mucho menos polifonía"; "nosotros consideramos que las ideas no son como los productos materiales intercambiables en el mercado", "Por otro lado nos preguntamos, cuando se sataniza el eurocentrismo: ¿a qué centro se refiere Fornet?", "Lo que tiene que darse primero es sobre todo, la voluntad de cambio, no del oprimido sino el opresor [...] La voluntad de cambio, se tiene que dar, sobre todo, de parte de los ricos [...] Que se dé un cambio, no es posible. Consideramos en todo caso que Raúl Fornet Betancourt, debió haber escrito un libro para el mundo y los filósofos germanos o europeos donde vive y trabaja. El título de su libro debió haber sido algo así: Transformación de la filosofía de los países del Norte", "Estamos de acuerdo en su discrepancia en la inculturación, por ello consideramos que el mejor camino para dilucidar y precisar dichas aproximaciones o diferencias, es recurrir al paralelo entre las raíces del pensamiento occidental y andino a través del análisis del lenguaje, caso del quechua o runasimi, quizá única manera de garantizar la autenticidad andina”; " Nosotros concebimos que la asimilación de lo diferente a lo universal, no se puede dar por solidaridad. Por solidaridad no se podría admitir, lo incorrecto como correcto, lo peor por lo mejor, lo inapropiado por apropiado, lo falso por verdadero; admitir lo particular como universal”; " Terminamos nuestro breve comentario señalando que las propuesta de Raúl Fornet Betancourt no es nada nuevo, pues muchas corrientes, escuelas filosóficas han pretendido similar "novedad" y "originalidad"'” (pp.208,210,218,220). 
parte del corpus que se debe consultar para saber cuál es la agenda actual de la filosofía latinoamericana. Sin ser necesariamente una corriente marginal, carente de todo peso e influencia, hay que reconocer que, a pesar de los avances logrados, este grupo no ha conseguido aún una incidencia decisiva, ni a nivel temático [ $i$ "giro hacia lo intercultural” o "interculturalización del saber filosófico"?] ni tampoco institucional o estructural, en lo que podríamos Ilamar la cultura oficial dominante de la filosofía latinoamericana ${ }^{23}$

Cabríamos preguntarnos en qué sentido"menores" ¿Por la cantidad e importancia de su producción? No podría ser el caso de Fernando Ainsa nide Dina V. Picotti. ¿Por la calidad e interés de los aportes, aunque no abundantes cuantitativamente (quizá por la edad de los autores...)? Tampoco sería aplicable a ninguno /a de los mencionados: Josef Estermann, Diana de Vallescar, Ricardo Salas Astrain, Fidel Tubino. En fin, que mejor conviene examinar esos aportes con todo cuidado y abrir las puertas a su interlocución con cualesquiera otros producidos por quienes fueran sus autores/as.

\section{c. ¿Transformación de la filosofía?}

La renovación o, más ampulosamente, transformación de la filosofía no sólo culmina, sino que, permanece curiosamente muy semejante a la etnocéntrica filosofía eurocéntrica hegemónica hasta ahora en las academias "occidentales" $y$ afectando incluso a sus manifestaciones en muchas otras partes... Un ejemplo citado por Raúl, es el representado por el filósofo africano, nacido en Costa de Marfil, Paulin Hountondji, quien insiste férreamente en su eurocentrismo ${ }^{24}$. En fin, para Raúl, la interculturalidad:

23 Crítica intercultural de la filosofía latinoamericana actual Edicción de REB. Madrid, Trotta, 2004, pp.75,76 y 105-106, cursivas en el original. Según Josef Estermann este texto "[...] representa un ejemplo concreto de este diálogo que tanto reivindica la filosofía intercultural" (Josef Estermann, "Acerca de la crítica intercultural de la filosofía latinoamericana actual de Raúl Fornet- Betancourt" en: Intersticios. México, Universidad Intercontinental, año 11, n' 24, 2006, p.181).

24 Paulin Hountondji le publicamos en castellano uno de sus artículos hace ya varios años, " On 'African philosophy"' en: Prometeo. Guadalajara, Universidad de Guadalajara, año 2, n' 5, enero abril de 1986, pp.1733. Sobre filosofía africana y sus relaciones con el filosofar nuestro, remito a mis trabajos: "Africanness: a Latin American philosophical perspective" en: Latin American Report. South Africa, University of South Afirca, vol. 10, n'2, julio- diciembre de 1994, pp.4-9 y "How and why to foster the history of the philosophy in postcolonial contexts?" en: arleen Salles y Elizabeth Milán- Zaibert, The Role of the History of Philosophy in Latin American Philosophy. USA, State Univerisity of New York Press, 2005, pp.197-227.- 
[...] Representa más bien un movimiento programático constructivo para reescribir el mapa de la filosofía desde esos lugares que dan verdad y sus voces propias portadoras de memorias alternativas hasta ahora periféricas ${ }^{25}$ (Fornet-Betancourt, 2001, p. 16)

A pesar de múltiples señalamientos explícitos en contrario, tiendo a dudar de que no estemos una vez frente a desarrollos de Filosofía de la cultura, seguramente más elaborados en ciertos sentidos que sus manifestaciones anteriores. En todo caso, por otra parte, es muy difícil separar la propuesta intercultural de Raúl de una cierta Filosofía de la historia subyacente y mayormente implícita, que busca establecer el lugar de los pueblos sometidos, colonizados, excluidos en la historia en la historia mundial, frente a la globalización. Y no está mal, salvo que requiere explicitarlo cuidadosamente.

Es importante subrayar que, en ese esfuerzo, la reivindicación del mito no pasa de ser un modo de hablar, sin consecuencias todavía visibles para el filosofar en sentido intercultural. En ese sentido, ha replanteado el punto con mucha lucidez Carlos Lenkersdorf, cuando revalora el papel del nosotros y de la lengua como claves de acceso a la cosmovisión de los pueblos mayas en sus obras ${ }^{26}$.

Una transformación de la filosofía que no puede ser menos que una política de la filosofía, una transformación política de la filosofía y que, para serlo a cabalidad, exige transformaciones estructurales de nuestras sociedades hartas de dependencia, dominación, saqueo, violencias, abusos y arbitrariedades en exclusivo beneficio de las y los poderosos /as de este globo errante.

Cabría cerrar provisionalmente estas reflexiones recordando que en una entrevista editada recientemente Raúl se define como "compañerista", en lugar de liberal o comunitarista, y afirma taxativamente que "la interculturalidad no es mestizaje", dejando con ello abiertas sendas vías de fecundos y estimulantes desarrollos ulteriores ${ }^{27}$.

25 Transformación intercultural..., p.16.-

26 En uno de sus trabajos más recientes expone resumidamente su posición. CF." Los desafíos de la filosofía para el siglo XXI" EN: Pensares y Quehaceres. Revista de políticas de la filosofía. México,AIFyP/SECNA/ Eón, n'1, mayo-octubre 2005, pp.7-29.

27 Aránzazu Oviedo García, "Raúl Fornet - Betancourt: La fecundidad de la filosofía latinoamericana" en: Utopía y Praxís Latinoamericana. Maracaibo, Universidad del Zulia, año 11, n’ 34, julio-septiembre 2006, 


\section{Referencias}

Ardiles, Osvaldo, Vigilia y utopía. (1980). Problemas de la filosofía contemporánea. Guadalajara: Universidad de Guadalajara.

Cerutti Guldberg, Horacio. (2006). Configuraciones de un filosofar sureador. México: Ayuntamiento de Orizaba, Veracruz.

Cerutti Guldberg, Horacio. (2006). Filosofía de la Liberación latinoamericana. México, FCE.

De Vallescar Palanca, Diana (2001). Raúl Fornet - Betancourt (1946). Clara Alicia Jalif de Bertranou, Semillas en el tiempo. El latinoamericanismo filosófico contemporáneo. Mendoza: EDIUNC.

Estermann, Josef (2006). Acerca de la crítica intercultural de la filosofía latinoamericana actual de Raúl Fornet- Betancourt. Intersticios. México: Universidad Intercontinental, año 11, N 24.

Forment, Eduardo (Coord.). (1987). Filosofía de Hispanoamérica. Aproximaciones al panorama actual. Barcelona: Universitat/ICE/PPU.

Fornari, Anibal. (2006) La pregunta por el sujeto histórico. Consideraciones preliminares sobre su exigencia socio-política y su problemática historicidad. Utopía y praxis latinoamericana. Maracaibo, Universidad del Zulia, año $11, N^{\circ} 35$, octubre-diciembre.

pp.134 y 136. Me permito consignar a continuación algunas otros trabajos consultados de relevancia para abundar en estos tópicos: a) de Raúl: "Zur Geschichte und Entwicklung der lateinamerikanischen Philosophie der Befreiung" en: Concordia. Frankfurt, Peter Lang. 1985, 156 págs.; Philosophie und theologie der Befreiung. Frankfurt, Materialis Verlag, 1987,112 págs.; R F-B und Alfredo Gómez Muller (Hrsgs.), Positionen Lateinamerikas. Franfurt, Materialis Verlag, 1998, 146 págs; "Notas sobre el sentido de la pregunta por una filosofía americana y su contexto histórico-cultural" en: Antonio Heredia Soriano (coordinador del seminario y edición), Actas del V Seminario de Historia de la Filosfía Española. Salamanca, Universidad de Salamanca, 1998, pp.437-445.; (Hrsg.), Diskursethik oder Befreiungsethik? Aachen, Concordia,1992, 207 págs.; (Hrsg.), Die Diskursethik und ihre lateinamerikanische Kritik. Aachen, Concordia, 1993, 262 págs; (Hrsg.), Quo vadis, Philosophie? Antworten der Phiosophen. Dokumentantion einer Weltumfrage. Aachen, Concordia, 1999, 337 págs.; Theologie im III. Millennium Quo vadis? Antworten der Theologen. Dokumentantion einer Weltumfrage. Frankfurt, Iko, 2000, 308 págs. De otras autorías: Odilón Guillén Fuentes, “ La identidad cultural en el pensar filosóficoandino” en: Sullull. Revista de Filosfía. Lima, UNMSM, año 3 , n'3, septiembre 2005, pp.25-39; Antonio Sidekum, Ethik als Transzendenrfahrung. Emmanuel Levinas und die Philosophie der BEFREIUNG. Aachen, Concordia, 1993, 210 págs.- 
Fornet-Betancourt, Raúl. (2000). Interculturalidad y globalización. Ejercicios de críticas filosóficas interculturales ene I contexto de la globalización neoliberal. Frankfurt: IKO/DEI.

Fornet-Betancourt, Raúl (2001). Transformación intercultural de la filosofía. Ejercicios teóricos y prácticos de filosofía intercultural desde Latinoamérica en el contexto de la globalización. Bilbao: desclée de Brouwer.

Fornet-Betancourt, Raul (1998). Tesis para la comprensión y práctica de la interculturalidad como alternativa a la globalización. Antonio Jiménez García (editor), Estudios sobre Historia del Pensamiento Español. Santander, Asociación de Hispanismo Filosófico/ Fundación Histórica Tavera/ Sociedad Menéndez Pelayo, 1998, pp. 387-394.

Fornet-Betancourt, Raul. (2004). Crítica intercultural de la filosofía latinoamericana actual. Mdrid:Trotta.

Galindo López, Olga. (1991) La filosofía inculturada ¿una alternativa social para América Latina? Islas. La Habana: Universidad Central de las Villas, Santa Clara, Cuba, n' 99, mayo, pp.5-14.

Giorgis, Liliana. José Martí. (2006) El humanismo como filosofía como filosofía de la dignidad. Mendoza: Ediciones del ICALA.

Gómez Müller, Alfredo. (2005). Sartre de la nausée á l' engagement. París: Editions du Félin.

Guadarrama González, Pablo y Pereliguin, Nokolai. (1998). Lo universal y lo específico en la cultura. Bogotá: Universidad Central de las Villas, Santa Clara, Cuba/ Universidad INCCA de Colombia.

Iriarte Concha y Naval Concepción. (2006). En torno a la educación intercultural en el ámbito escolar en España. Graciela A. Mota (coordinación y edición), Educación cívica y ciudadana: una visión global. Dignidad, identidad y participación en la construcción de sociedades democráticas. México: Aula XXI/Santillana. 
Mejía Huamán, Mario. (2005). Transformación intercultural de la filosofía. Comentario desde la óptica de la filosofía. Comentario desde la óptica andina. Hacia una filosofía andina. Doce ensayos sobre el componente andino de nuestro pensamiento. Lima: edición del autor.

Löwy Michael. (1995). O marxismo na América Latina. Traducao Egídio F. Schmitz. Sao Leopoldo, RS, unisinos.

Obando Morán, Octavio. (2000). Mundialización, interculturalidad y desenvolvimiento de algunos problemas filosóficos en la tradición socialista del Perú: 1970-2000. Reflexión y crítica. Revista de filosofía. Lima, UNMSM. Septiembre año $9, \mathrm{~N}^{\circ} 5$.

Salas Astrain, Ricardo (Coord.). (2005). Marxismo y filosofía. Pensamiento Crítico Latinoamericano. Conceptos Fundamentales. Santiago de Chile: Ediciones Universidad Católica Silva Henríquez.

Vidal Alva, Dora. (2003). La filosofía intercultural y la filosofía latinoamericana. Reflexión y crítica. Revista de Filosofía. Lima, UNMSM. Marzo, año 7, № 3. 